\title{
Ocean currents as a potential dispersal pathway for Antarctica's most persistent non-native terrestrial insect
}

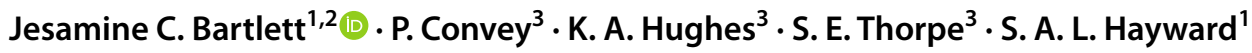

Received: 20 December 2019 / Revised: 17 December 2020 / Accepted: 17 December 2020 / Published online: 8 January 2021

(c) The Author(s) 2021

\begin{abstract}
The non-native midge Eretmoptera murphyi is Antarctica's most persistent non-native insect and is known to impact the terrestrial ecosystems. It inhabits by considerably increasing litter turnover and availability of soil nutrients. The midge was introduced to Signy Island, South Orkney Islands, from its native South Georgia, and routes of dispersal to date have been aided by human activities, with little known about non-human-assisted methods of dispersal. This study is the first to determine the potential for dispersal of a terrestrial invertebrate species in Antarctica by combining physiological sea water tolerance data with quantitative assessments of ocean current journey times. Fourth instar larvae tolerated sea water submergence for up to 21 days, but submerged egg sacs had significantly reduced hatching success. Using near-surface drifter data, we conclude that ocean current dispersal from Signy Island would not present a risk of species transfer beyond the South Orkney Islands on the tested timescales. However, if E. murphyi were to be introduced to the South Shetlands Islands or Adelaide Island, which are located offshore of the Antarctic Peninsula, there would be a risk of successful oceanic dispersal to neighbouring islands and the Antarctic Peninsula mainland. This study emphasises the need for effective biosecurity measures and demonstrates the role that currently undocumented pathways may have in dispersing non-native species.
\end{abstract}

Keywords Near-surface drifters $\cdot$ Chironomidae $\cdot$ Salinity tolerance $\cdot$ Invasive species $\cdot$ Insect $\cdot$ Physiology $\cdot$ Climate change

\section{Introduction}

Non-native species are one of the largest threats to global biodiversity (Pyšek et al. 2020). Understanding their pathways for dispersal is crucial to ensuring that adequate management and biosecurity measures can be put in place. Invasive species can be particularly impactful in the simple terrestrial ecosystems of the polar regions (e.g. Ernsting et al. 1995; Hänel and Chown 1998), and the risk of their

Supplementary Information The online version contains supplementary material available at https://doi.org/10.1007/s0030 0-020-02792-2.

Jesamine C. Bartlett

jesamine.bartlett@nina.no

1 University of Birmingham, Birmingham B15 2TT, UK

2 Present Address: Norwegian Institute for Nature Research, 7034 Trondheim, Norway

3 Natural Environment Research Council, British Antarctic Survey, Cambridge CB3 OET, UK introduction is increasing with rising levels of human activity as well as climate change which is likely to further promote establishment and dispersal (Duffy et al. 2017).

The flightless, parthenogenetic, midge Eretmoptera murphyi (Orthocladiinae, Chironomidae) is thought to be Antarctica's most persistent non-native insect, having been introduced to Signy Island (South Orkney Islands, $60^{\circ} \mathrm{S}$ ) from its native South Georgia $\left(54^{\circ} \mathrm{S}\right)$, most likely during plant transplant experiments carried out in the 1960s (Block et al. 1984). Since its introduction and subsequent discovery in the 1980s, this detritivorous midge has expanded its distribution to cover an area of $85,000 \mathrm{~m}^{2}$, with population densities locally exceeding 100,000 larvae $\mathrm{m}^{-2}$, resulting in significant increases in nitrate levels within previously nutrient-limited soils (Bartlett 2019; Bartlett et al. 2019). The current distribution of E. murphyi on Signy Island includes the same peninsula as the United Kingdom's Signy Research Station, and broadly includes most of the peninsula in areas close to the coast, including the supralittoral zone (Bartlett et al. 2019). Thus, loose substrate containing E. murphyi can readily be moved to 
the shoreline in surface run-off, especially during periods of snowmelt or heavy rain, which are increasing due to climate change (Larsen et al. 2014; King et al. 2017). The presence of seabirds and seals in known E. murphyi habitats will also increase the likelihood of transfer into the sea, or exposure to sea water through ectozoochory. If this species is able to survive exposure to sea water for extended periods, then the possibility exists for transfer to other parts of the coastlines on Signy Island, or to adjacent islands, via animal vectors or local marine currents. Such transfer has been noted in the flightless terrestrial invasive beetle Merizodus soledadinus in the sub-Antarctic Kerguelen Islands. Since its likely introduction in 1913, the beetle has colonised several small islands in the archipelago with no apparent human assistance (Lebouvier et al. 2020), with its tolerance to sea water submersion supporting the potential dispersal mechanism of marine drifting.

Eretmoptera murphyi already appears to be spreading to other areas of Signy Island along terrestrial pathways, with the north-western coast (that hosts some of the best-known examples of Antarctic moss banks) the most likely area to be colonised next (Bartlett et al. 2019). The northern part of the island is typically accessed on foot by traversing a short, shallow, subtidal crossing, immediately entering areas identified as medium to high risk for establishment (Bartlett et al. 2019). Recently, E. murphyi larvae were found to tolerate dilutions of sea water over several days, suggesting that this intertidal crossing, and short periods in sea water, may not limit larval dispersal (Bartlett et al. 2020a). Eretmoptera murphyi's nearest relative, the flightless endemic maritime Antarctic chironomid Belgica antarctica, can tolerate 10 days of hyperosmotic exposure in $200 \%$ sea water (Elnitsky et al. 2009). This is thought to be an adaptation to high salinity conditions that can occur in the supralittoral zone, where the species can often be found, as sea water evaporates from shallow rock pools or vegetation. Given that E. murphyi also occupies supralittoral habitats, we hypothesised that it will have a salinity tolerance and capacity to survive seawater submergence comparable to $B$. antarctica, as well as exposure to higher salinity, as would also be encountered in oceanic rafting scenarios.

Rafting is a known behavioural tactic in invertebrates of both freshwater and marine environments, including the Magellanic sub-Antarctic chironomid Telmatogeton magellanicus (Simões et al. 2020), and Antarctic and Arctic Collembola (Coulson et al. 2002; Hawes et al. 2008). There is evidence of invertebrate rafting both with and without debris, especially in Collembola, and this has been proposed as a potentially important dispersal pathway for flightless species (Coulson et al. 2002; Hawes et al. 2008). Rafting may explain the distribution of $B$. antarctica across many small islands and patches of ice-free ground along the Antarctic Peninsula (Gantz et al. 2018).
Signy Island has been the location of a British Antarctic Survey (BAS) research station since 1947 and, previously, a small industrial whaling station. It is part of a logistical supply network that links multiple locations in the Southern Ocean, Antarctic Peninsula and the continental coastline. Pertierra et al. (2020) highlight areas on the Antarctic Peninsula that are at most risk of invasion by $E$. murphyi based on currently favourable habitats under existing climatic conditions, and the level of human activity/routes associated with existing E. murphyi populations. They demonstrate that the midge could pose a high risk to several areas, especially in the South Shetland Islands and islands close to the BAS Rothera Research Station on Adelaide Island in Marguerite Bay, where there are high levels of human activity and logistical connections with South Georgia and the South Orkney Islands. One incident has already been recorded where living E. murphyi larvae were inadvertently transferred in soil from South Georgia to Rothera Research Station; however, this is not thought to have led to establishment (Hughes et al. 2010).

In this study we examine the ability of E. murphyi larvae and eggs to survive in seawater for a period sufficient to allow dispersal via ocean currents. The data are then interpreted in the context of range expansion on Signy Island, as well as potential dispersal elsewhere in the South Orkney Islands and to key locations on the Antarctic Peninsula and offshore islands.

\section{Materials and methods}

\section{Sample collection}

Eretmoptera murphyi larvae were collected from Signy Island during the 2016/17 austral summer. Samples were kept on soil substrate from their local habitat and returned to the United Kingdom by ship $\left(+4{ }^{\circ} \mathrm{C}, 10\right.$ weeks), where they were maintained under the same 'control' conditions at the University of Birmingham. Larvae were maintained, extracted and classified to instar following Bartlett et al. (2018). Larval submersion experiments used seawater from stocks at the British Antarctic Survey, Cambridge. Experiments using eggs were conducted in laboratories at Signy Research Station during January 2017, using recently laid egg sacs, and seawater collected locally. Freshwater was obtained by allowing Signy soil taken from E. murphyi habitats to leach into deionised water (1:3 soil:water) for at least two weeks, thereby reflecting local hydrological conditions as closely as possible. In both instances, $\mathrm{pH}$ and salinity were determined using a Hanna combi metre-HI-98129 (Hanna Instruments Ltd, Leighton Buzzard). There were no significant differences between the $\mathrm{pH}$ and salinity values of seawater 
samples collected in the field vs. the laboratory stocks (pH: Mann-Whitney $U=7, p=0.3$; Salinity: Mann-Whitney $U=12, p>0.99$ ).

Egg sacs were removed from the substrate as described by Bartlett et al. (2018). All eggs within the egg sacs were confirmed to be at the first (opal) developmental stage prior to the start of experiments and were then used for the entire egg development period of 35 days (Bartlett et al. 2018). If any eggs showed signs of yellowing or embryonic development the entire egg sac was discarded and not used for experimentation.

\section{Salt-water immersion tolerance}

Three groups of ten fourth instar larvae (L4) were placed in covered Petri dishes, submerged at $4{ }^{\circ} \mathrm{C}$ in either $100 \%$ seawater (PSU 35.9), 0\% seawater (field/freshwater), or placed in moist Signy soil. Additionally, to provide a comparison with $B$. antarctica (Elnitsky et al. 2009), a 200\% salinity (PSU 70) treatment was also used. For this, $100 \mathrm{~mL}$ of seawater was evaporated to salt crystals and those salt crystals dissolved in a further $100 \mathrm{~mL}$ of seawater. Survival of the immersed larvae was monitored after 2, 7, 14 and 21 days continuous immersion. Larval survival was determined $72 \mathrm{~h}$ after exposure by assessing movement or reaction to stimulation with a fine paintbrush. Survival of larvae has previously only been tested in freshwater submergence (Everatt et al. 2014), but unlike Everatt et al. (2014), we used field water, as opposed to pure (distilled) water, which would pose additional osmotic challenges. Considering the known ability of the midge larvae to survive for 28 days in distilled water (Everatt et al. 2014), we consider that 21 days immersion in water obtained from the saturated moss banks in which the larvae occur naturally is a suitable immersion control against seawater immersion. After each treatment, individuals were removed and placed in a Petri dish containing moist Signy soil substrate and kept at control conditions in a dark refrigerator at $4{ }^{\circ} \mathrm{C}$.

Three groups of ten egg sacs were submerged for the full egg development period of 35 days at $4{ }^{\circ} \mathrm{C}$ in either a soil control, $0 \%$ (freshwater) or $100 \%$ seawater. The individual eggs within the egg sacs were monitored for hatching every $48 \mathrm{~h}$, until the end of the 35 days period. Egg development and survival were assessed throughout, with the egg sacs producing L1 hatchlings that were capable of escaping the egg sac matrix considered 'hatched'.

All data were analysed using Prism 9.0 and tested for normality with the D'Agostino and Pearson test prior to log-transformation or use of a non-parametric test (where appropriate).

\section{Oceanic drifter data}

Satellite-tracked surface drifting buoys, drogued at $15 \mathrm{~m}$ depth, provide data on potential dispersal pathways and timescales of transport of material in the near-surface layer of the ocean. Previous studies have successfully used drifter data to map the circulation on the shelf of the Antarctic Peninsula (Beardsley et al. 2004; Thompson et al. 2009). Here we examined the trajectories of all drifters available through the Global Drifter Program (Lumpkin and Centurioni 2019) as of June 2018 that passed close to the South Orkney Islands, South Shetland Islands, and within Marguerite Bay $(n=97)$. These were identified as key areas of interest by Pertierra et al. (2020), to determine potential dispersal on timescales relevant to E. murphyi. The drifter data were quality controlled and interpolated to $6 \mathrm{~h}$ intervals as part of the data processing, and only data from drifters that still had their drogues attached were used in our analysis.

\section{Results}

\section{Salt-water immersion tolerance}

\section{Larvae}

A mixed effects model, with Dunnet's correction for multiple comparisons, found no difference between the treatments and the soil control over time, except for the hyperosmotic treatment where larval survival was reduced to $26 \%$ after 2 days ( $200 \%$ vs. Soil at 14 days, $p=0.0005$; and at 21 days, $p=0.0035$ ). All other treatments showed no significant difference to the soil control at any time point (Fig. 1).

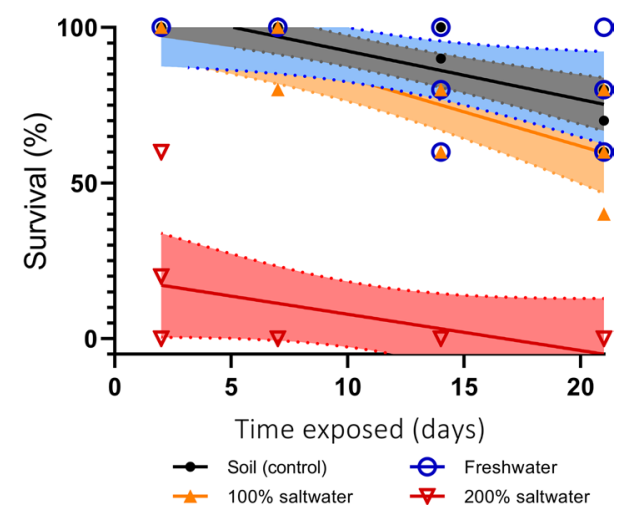

Fig. 1 Larval survival (linear regression with 95\% CI) of exposure to soil control, freshwater, 100\% seawater (PSU 35.9) and 200\% seawater (PSU 70). Data points shown as the mean replicate survival ( $3 \times 10$ individuals) at $2,7,14$, and 21 days exposures 
Eggs There was no difference in the survival of eggs in the soil control and those submerged in freshwater for 35 days (soil vs. $0 \%$, Mann-Whitney $U=50, p>0.99$; Fig. 2), with nearly all going on to successfully hatch. However, egg survival in seawater was significantly reduced, with just a $10 \%$ hatching success by the end of the egg development period (soil vs. $100 \%$ seawater, Mann-Whitney $U=0, p<0.0001$ ). Eggs continued to develop in all treatments, with hatching commencing by day 20 across soil, freshwater and seawater (Fig. 2). However, the effect of seawater was evident upon hatching, with those hatchlings that did survive to emergence dying soon after exposure to seawater, if they successfully escaped from the egg casing at all. We noted a small proportion of eggs visibly shrivelling through development, but most of those that did develop to hatching then died with their heads external to the casing as they attempted to emerge.

\section{Oceanic drifter data}

A total of 97 drifters were assessed across three areas relevant to potential E. murphyi dispersal (Fig. 3a). Figure 3b-d illustrate several areas that are relevant to this study and reflect the overall trends of currents in these areas (drifter ID information in Online Resource 1). Drifters that passed close to Adelaide Island were advected towards the mainland of the Antarctic Peninsula (Fig. 3b). Circulation within Marguerite Bay connected the offshore islands with the Antarctic Peninsula on timescales of less than 20 days (Fig. 3b). Drifter 'Rothera blue' was notably rapid, travelling $~ 90 \mathrm{~km}$ in less than 10 days, passing through the Faure Islands in

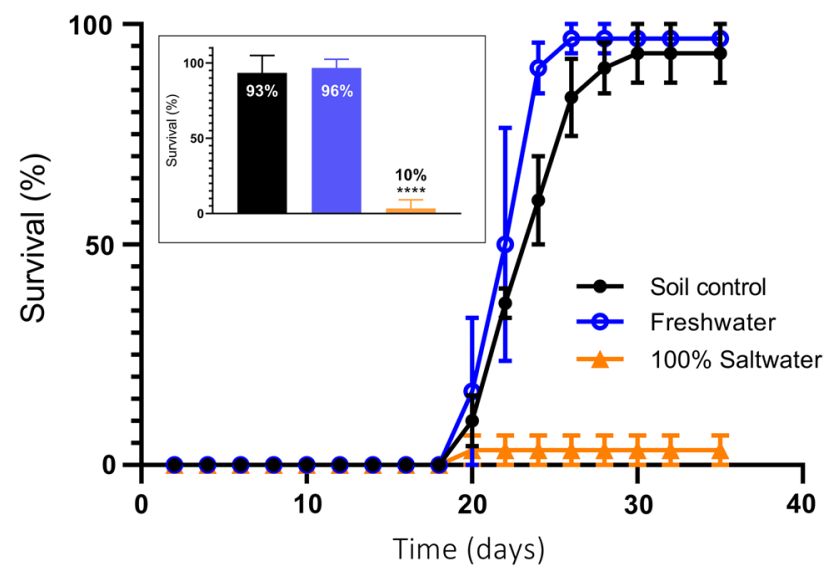

Fig. 2 Hatching of eggs within egg sacs through the maximum egg development period (35 days-Bartlett et al. 2018), when exposed to a soil control, submerged in freshwater or in $100 \%$ seawater (PSU $38)$. Data shown as the replicate mean ( $\pm \mathrm{SEM}, n=30$ per treatment). Inset shows the final hatching results for each treatment, where seawater is significantly different to the control (soil vs. $100 \%$ seawater, Mann-Whitney $U=0, p<0.0001$; soil vs. freshwater, Mann-Whitney $U=50, p>0.99$ ) central Marguerite Bay. 'Rothera red' looped Marguerite Bay, travelling $113 \mathrm{~km}$ in 20 days, passing through the Dion Islands and Millerand Island before looping back up to the Faure Islands (Fig. 3b).

Few drifters passed close to Signy Island itself, but those that reached the South Orkney Plateau were transferred across the shelf on a range of timescales. Local processes either retained the drifters on the shelf or moved them rapidly off-shelf, where they became entrained into the anticyclonic flow around the plateau before continuing northeastwards across the Scotia Sea (Fig. 3c). Current transfer onto the South Orkney Plateau originated from the west or south-west of the plateau.

Drifters in the South Shetland Islands (SS) region demonstrated a complex near-surface circulation. Numerous pathways for potential dispersal to new habitats exist (Fig. 3d), with transfer possible between all islands of the archipelago, and further south, on timescales of 10-30 days. Water movement between King George Island and Elephant Island can take as little as 10 days (Drifter track 'SS purple', Fig. 3d), with a fast north-east moving current running the length of the South Shetland Islands. Drifter track 'SS orange' illustrates currents weaving through the archipelago and staying close to the islands: from the north of King George Island, water can move to Robert Island within 10 days, and then on to Livingston Island. From here the water can move quickly around western Livingston Island and back north-eastward along the length of the archipelago, taking a further 10 days to reach the southern coast of King George Island (Fig. 3d). Drifter track 'SS blue' illustrates a southwards current from western Livingston Island to the islands at the north-eastern extent of the Palmer Archipelago, taking 20 days. From here the currents can weave south-west through the archipelago to Brabant Island, contacting several smaller islands every 10 days or less (Fig. 3d).

\section{Discussion}

The survival of mature (L4) E. murphyi larvae in 100\% seawater for as long as 21 days indicates that seawater exposure alone would not necessarily be a barrier to this species' dispersal. However, whilst mature larvae tolerated prolonged submergence, the small L1 larvae were unable to survive even very brief seawater exposure if they successfully hatched from the immersed eggs (Figs. 1, 2).

Most dipteran larvae cannot tolerate prolonged seawater submergence (Bayley 1972). However, larvae of B. antarctica, Antarctica's only endemic chironomid (and E. murphyi's closest relative), can withstand extensive osmotic dehydration, with $50 \%$ survival after 10 days in $100 \%$ seawater (Elnitsky et al. 2009). As predicted, E. murphyi L4 larvae also showed considerable tolerance to seawater 
immersion, with no difference in survival between $100 \%$ seawater, freshwater or soil treatments over 21 days (Fig. 1). This is consistent with the findings of a recent, related study of the possibility of using seawater as a biosecurity measure, where E. murphyi larvae survived all seawater dilution treatments trialled over a 7 days period (Bartlett et al. 2020a). The mortality recorded in the current, longer, study is also consistent with previous findings relating to E. murphyi's life cycle and development under field and controlled conditions (Bartlett et al. 2018). Survival of E. murphyi L4 larvae declined rapidly under prolonged hyperosmotic sea water (200\%) exposure, with time to $50 \%$ mortality $\left(\mathrm{LT}_{50}\right)$ of just 2 days. While $B$. antarctica survival also declined rapidly under these conditions, $25 \%$ of larvae survived $6 \mathrm{~d}$ submerged in 200\% sea water (Elnitsky et al. 2009), suggesting a greater tolerance of hyperosmotic stress in the more southern species. This lower tolerance may limit the ability of the E. murphyi larvae to survive in some habitats currently occupied by $B$. antarctica, such as supralittoral habitats that can experience hypersaline conditions resulting from tidal spray and evaporation (Elnitsky et al. 2009).

The ability of E. murphyi L4 larvae to survive periods of at least 21 days in seawater opens the possibility of oceanic dispersal to adjacent islands. Providing hyperosmotic conditions are not experienced for longer than a few days, this could occur through rafting (most likely with debris such as mosses washed into the sea, as larvae alone would sink rather than float) or via zoochoric association with seabirds or seals. Given E. murphyi is found in habitats with close association with elephant and fur seals on Signy Island (Bartlett et al. 2019) as well as various nesting seabirds, animal transport of larvae is certainly possible. There is also the potential that eggs may be carried in the fur or feathers of the animals, especially as egg sacs have a sticky outer membrane (Bartlett et al.2018), and thus could enter the ocean via this route. Whilst exposure to seawater appears to prevent successful hatching, our data indicated that eggs can continue development while submerged, and thus, both egg sacs and L4 larvae could represent potentially viable oceanic dispersal stages (Fig. 2). This would be especially likely if egg sacs are returned to terrestrial environments within the egg development period, such as is possible if transported through ectozoochory. Within this study, we only examined eggs, and consequently L1 hatchlings, as well as the mature L4 larvae; it is possible that L2 and L3 instars are not as vulnerable to seawater as are L1, given their more robust response to other stressors, such as cold (Bartlett et al. 2020b).

Buoyancy of the midge larvae was variable within this experiment, with some sinking and others not. However, we did not explicitly examine buoyancy. Even early stage pupae have a hydrophobic cuticle (J. Bartlett pers. obs), as well as later pupal stages and adults, likely as a result of the development of microtrichia during metamorphosis as is seen in several intertidal Chironomidae (Neumann and Woermann 2009). Based on this knowledge we speculate that pupae or adults might be capable of physically floating on the surface, although we also note that adults, in particular, are very short lived, thus limiting the dispersal potential of this stage relative to water transfer times. Egg sacs and larvae would, rather, likely be reliant on vectors such as animals, or rafts/debris.

Drifter currents crossing the South Orkney Plateau move material into open ocean (Fig. 3c), posing little risk of transporting the midge beyond the South Orkney Islands. The available drifter data did not include tracks from within the South Orkney Island group, so the details of currents around Signy Island and its neighbouring islands remain unknown. However, we did identify several currents that could potentially allow dispersal of $E$. murphyi among islands along the Antarctic Peninsula, should the midge be initially transferred to this region-as has happened in the past (Hughes et al. 2010). The South Shetland Islands are a well frequented archipelago north-west of the tip of the Antarctic Peninsula, with 26 international research stations located across several islands, as well as many field research and tourist landing sites (Bender et al. 2016); King George Island alone hosts the facilities of ten different national operators (COMNAP 2019). The geography of the South Shetland Islands means that distances between islands are small, and available coastlines large. Figure $3 \mathrm{~d}$ shows how the midge could potentially disperse among the islands of the archipelago, including to Elephant Island in the north, and from Livingston Island southwards into the Palmer Archipelago, via smaller islands en route that could act as stepping stones. If transferred to Rothera Research Station (Adelaide Island) via anthropogenic means, there are potential pathways from there towards the mainland of the Antarctic Peninsula and its offshore islands (Fig. 3b), and transfer could occur well within the survival period of E. murphyi larvae in seawater (Fig. 3b, blue drifter).

To date, aeolian transport has most commonly been invoked in the colonisation of islands and remote areas by terrestrial invertebrates (e.g. Peck 1994; Hogg and Stevens 2002). Hughes and Worland (2010) considered that E. murphyi could potentially be wind dispersed on Signy Island, or via the feet of birds. However, the detailed distribution mapping of Bartlett et al. (2019) found that the species' current distribution on the island is effectively explained through dispersal via human movement. Passive aeolian dispersal of adult Chironomidae has previously been suggested as a form of trans-oceanic movement (Krosch et al. 2011). Epizoochory has also been proposed as a dispersal mechanism that could help explain the distribution of some Antarctic Acari (Pugh 1997). Given the potential of both E. murphyi and $B$. antarctica to survive prolonged periods of seawater exposure, and the pattern of ocean currents in the region, it 

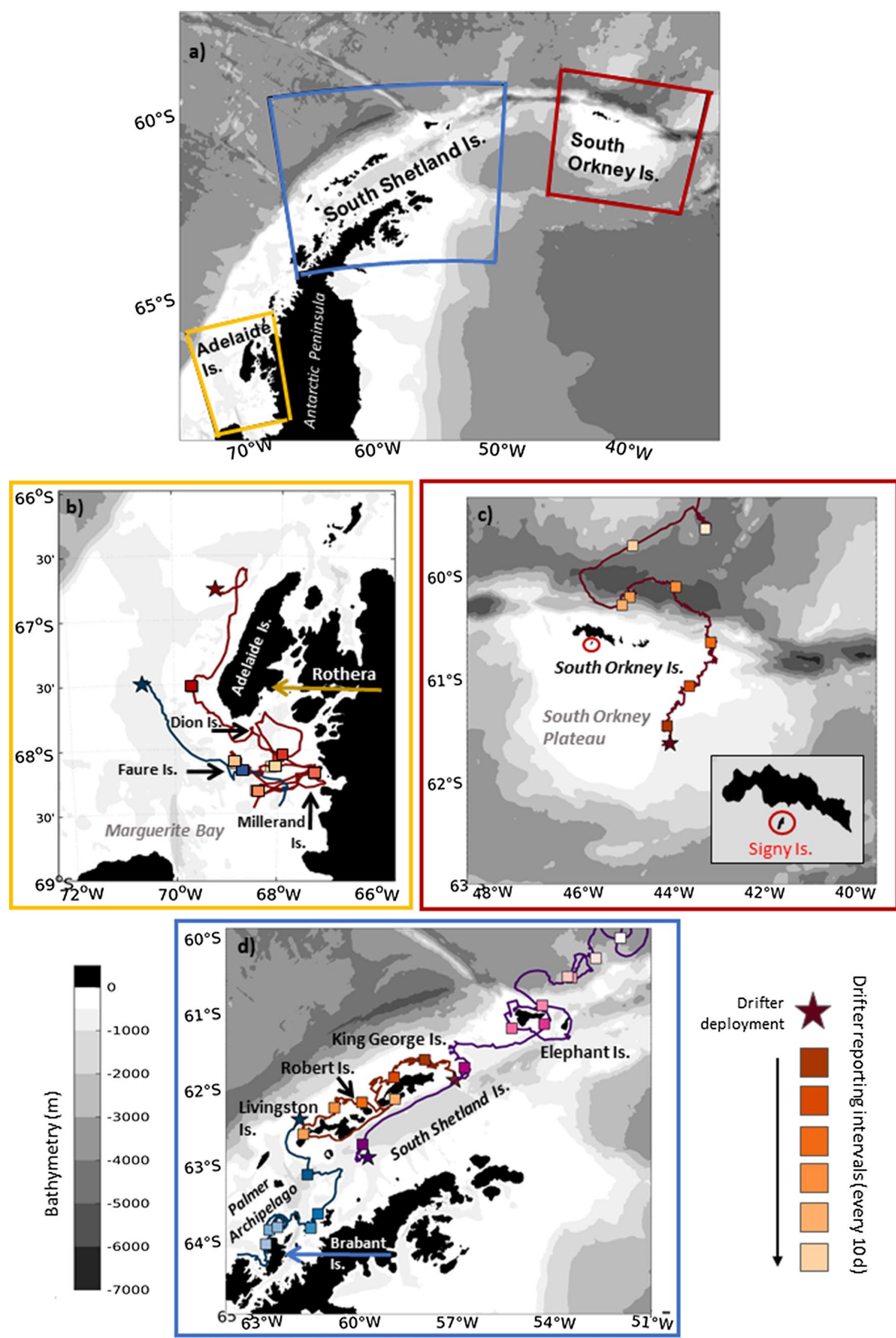
४Fig. 3 Near-surface drifter trajectories from regions relevant for $E$. murphyi dispersal, see Online Resource 1 for drifter ID information: a Positions of South Orkney Islands, South Shetland Islands and Adelaide Island in relation to the northern Antarctic Peninsula; b The Antarctic Peninsula region of Marguerite Bay around Adelaide Island, including Rothera Research Station (UK), showing two drifter tracks; c The South Orkney Plateau, insert showing location of Signy Island, and one drifter track; d The South Shetland Islands showing King George Island and Livingston island, with Elephant Island to the north-east, and three drifter tracks. Deployment location of each drifter is marked with a star, and squares mark 10 days intervals along each track with shading becoming lighter with time. Bathymetry from the GEBCO 2014 dataset (m). Key ports/stations and islands of interest are labelled

is reasonable to infer that the distribution of $B$. antarctica along the Antarctic Peninsula could be explained, in part, by oceanic drifting/rafting, and that this cannot be excluded as a potential distribution pathway for seawater tolerant invertebrate species, now including E. murphyi. Belgica antarctica is currently distributed throughout the coastal regions of the western Antarctic Peninsula to southern Marguerite Bay (Allegrucci et al. 2005; Gantz et al. 2018). With its known ecophysiological pre-adaptations, given opportunity, E. murphyi could in principle occupy the same distribution (Pertierra et al. 2020). Both E. murphyi and B. antarctica have similar life cycles, physiological tolerances and, potentially, diets (Baust and Edwards 1979). However, a key difference is that $E$. murphyi is parthenogenetic and able to emerge over a much more extended period in the summer, rather than in a more time-constrained event as is the case for $B$. antarctica [compare Bartlett et al. (2018) with Sugg et al. (1983)]. This may give E. murphyi a competitive advantage and allow it to increase in population numbers more rapidly. Similar scenarios in temperate invertebrates have seen parthenogenetic species invade twice as rapidly as sexual species, and invading species often outcompete native organisms they may share a niche with (e.g. Vorburger et al. 2003).

\section{Conclusions}

Mature larvae of the non-native midge E. murphyi have the ability to survive seawater immersion for at least three weeks. As well as facilitating a potential for short distance dispersal originating from its present distribution on Signy Island, analysis of near-surface ocean currents highlights the risk that further human-assisted transfer of the midge to either Marguerite Bay or the South Shetland Islands could pose. This would potentially give the midge a route to colonise many islands, as well as the mainland of the Antarctic Peninsula. Modelling studies at high spatial and temporal resolution, as well as further behavioural and physiological studies, are required to provide more robust assessment of the level of this risk. This study highlights the need for the implementation of rigorous biosecurity measures, particularly for personnel or equipment routing to these areas from the South Orkney Islands or South Georgia.

Acknowledgements J. Bartlett was funded by the Natural Environment Research Council (NERC) through The Central England NERC Training Alliance (CENTA DTP) (RRBN19276) and is currently supported by the Norwegian Institute for Nature Research (NINA). Her PhD studentship was supported by the University of Birmingham and the British Antarctic Survey (BAS). P. Convey, S. Thorpe and K. Hughes are supported by NERC core funding to the BAS 'Biodiversity, Evolution and Adaptation' and 'Ecosystems' Teams, and Environment Office, respectively. The Global Drifter Program data were made available by the National Oceanic and Atmospheric Administration Atlantic Oceanographic and Meteorological Laboratory Physical Ocean Division (NOAA AOML PhOD). General Bathymetric Chart of the Oceans (GEBCO) bathymetry data are available from www.gebco.net. This study contributes to the 'Integrated Science to Inform Antarctic and Southern Ocean Conservation' research programme (Ant-ICON) of the Scientific Committee on Antarctic Research (SCAR). We thank Nicholas Teets and an anonymous reviewer for their helpful and constructive comments that improved this manuscript.

Funding The funding was supported by Natural Environment Research Council (Grant No. RRBN19276) and British Antarctic Survey (Grant No. CASS121).

\section{Compliance with ethical standards}

Conflict of interest The authors confirm there to be no conflict of interest and that no ethical standards were breached in the course of this study.

Open Access This article is licensed under a Creative Commons Attribution 4.0 International License, which permits use, sharing, adaptation, distribution and reproduction in any medium or format, as long as you give appropriate credit to the original author(s) and the source, provide a link to the Creative Commons licence, and indicate if changes were made. The images or other third party material in this article are included in the article's Creative Commons licence, unless indicated otherwise in a credit line to the material. If material is not included in the article's Creative Commons licence and your intended use is not permitted by statutory regulation or exceeds the permitted use, you will need to obtain permission directly from the copyright holder. To view a copy of this licence, visit http://creativecommons.org/licenses/by/4.0/.

\section{References}

Allegrucci G, Carchini G, Todisco V, Convey P, Sbordoni V (2005) A molecular phylogeny of Antarctic Chironomidae and its implications for biogeographical history. Polar Biol 29(320):326

Bartlett JC (2019) The ecophysiology and ecosystem impacts of an Antarctic invader: The chironomid, Eretmoptera murphyi. University of Birmingham Doctoral thesis

Bartlett JC, Convey P, Hayward SAL (2018) Life cycle and phenology of an Antarctic invader: the flightless chironomid midge, Eretmoptera murphyi. Polar Biol 42:115-130

Bartlett JC, Convey P, Pertierra LR, Hayward SAL (2019) An insect invasion of Antarctica: the past, present and future distribution of 
Eretmoptera murphyi (Diptera, Chironomidae) on Signy Island. Insect Conserv Divers 13:77-90

Bartlett JC, Radcliffe RJ, Convey P, Hughes KA, Hayward SAL (2020a) The effectiveness of Virkon ${ }^{\circledR}$ S disinfectant against an invasive insect and implications for Antarctic biosecurity practices. Antarct Sci. https://doi.org/10.1017/S0954102020000413

Bartlett JC, Convey P, Hayward SAL (2020b) Surviving the Antarctic winter: life stage cold tolerance and ice entrapment survival in the invasive Chironomid midge Eretmoptera murphyi. Insects 11(3):147. https://doi.org/10.3390/insects11030147

Baust JG, Edwards JS (1979) Mechanisms of freezing tolerance in an Antarctic midge, Belgica antarctica. Physiol Entomol 4:1-5

Bayley IAE (1972) Salinity tolerance and osmotic behaviour of animals in athalassic saline and marine hypersaline waters. Ann Rev Ecol Syst 3:233-268

Beardsley RC, Limeburner R, Owens WB (2004) Drifter measurements of surface currents near Marguerite Bay on the western Antarctic Peninsula shelf during austral summer and fall, 2001 and 2002. Deep Sea Res II 51:1947-1964

Bender NA, Crosbie K, Lynch HJ (2016) Patterns of tourism in the Antarctic Peninsula region: a 20-year analysis. Antarct Sci 28:194-203

Block W, Burn AJ, Richard KJ (1984) An insect introduction to the maritime Antarctic. Biol J Linn Soc 23:33-39

COMNAP (2019) Information on station locations and personnel numbers. https://ucnz.maps.arcgis.com/apps/webappviewer/ index.html $\mathrm{id}=8663617 \mathrm{ffa} 264 \mathrm{e} 45 \mathrm{aa} 3804 \mathrm{~d} 0 \mathrm{~d} 08 \mathrm{fcdf} 8$. Accessed 26 Nov 2019

Coulson SJ, Hodkinson ID, Webb NR, Harrison JA (2002) Survival of terrestrial soil-dwelling arthropods on and in seawater: implications for trans-oceanic dispersal. Funct Ecol 16:353-356

Duffy GA, Coetzee BWT, Latombe G, Akerman AH, McGeoch MA, Chown SL (2017) Barriers to globally invasive species are weakening across the Antarctic. Divers Distrib 23:982-996

Ernsting G, Block W, Macalister H, Todd C (1995) The invasion of the carnivorous carabid beetle Trechisibus antarcticus on South Georgia (sub-antarctic) and its effect on the endemic herbivorous beetle Hydromedion spasutum. Oecologia 103:34-42

Elnitsky MA, Benoit JB, Lopez-Martinez G, Denlinger DL, Lee RE (2009) Osmoregulation and salinity tolerance in the Antarctic midge, Belgica antarctica: seawater exposure confers enhanced tolerance to freezing and dehydration. J Exp Biol 212:2864-2871

Everatt M, Convey P, Mirbahai L, Worland MR, Bale JS, Hayward SAL (2014) Can the Antarctic terrestrial midge, Eretmoptera murphyi, tolerate life in water? Ecol Entomol 39:732-735

Gantz JD, Spacht DE, Lee RE (2018) A preliminary survey of the terrestrial arthropods of the Rosenthal Islands, Antarctica. Polar Res. https://doi.org/10.1080/17518369.2018.1500266

Hänel C, Chown SL (1998) The impact of a small, alien invertebrate on a sub-Antarctic terrestrial ecosystem: Limnophyes minimus (Diptera, Chironomidae) at Marion Island. Polar Biol 20:99-106

Hawes T, Worland MR, Bale J, Convey P (2008) Rafting in Antarctic Collembola. J Zool 274:44-50

Hogg ID, Stevens MI (2002) Soil fauna of Antarctic coastal landscapes. In: Beyer L, Bolter M (eds) Geoecology of Antarctic ice-free landscapes. Springer, Berlin, pp 265-282
Hughes KA, Worland MR (2010) Spatial distribution, habitat preference and colonization status of two alien terrestrial invertebrate species in Antarctica. Ant Sci 22:221-231

Hughes KA, Convey P, Maslen N, Smith R (2010) Accidental transfer of non-native soil organisms into Antarctica on construction vehicles. Biol Invasions 12:875-891

King JC, Bannister D, Hosking JS, Colwell SR (2017) Causes of the Antarctic region record high temperature at Signy Island, 30th January 1982. Atmos Sci Lett 18:491-496

Krosch MN, Baker AM, Mather PB, Cranston PS (2011) Systematics and biogeography of the Gondwanan Orthocladiinae (Diptera: Chironomidae). Mol Phylogen Evol 59:458-468

Larsen JN et al (2014) Polar regions. In: Barros VR et al (eds) Climate change 2014: impacts, adaptation, and vulnerability. Part $\mathrm{B}$ : regional aspects contribution of working group II to the fifth assessment report of the intergovernmental panel on climate change. Cambridge University Press, Cambridge, pp 1567-1612

Lebouvier M, Lambret P, Garnier A, Convey P, Frenot Y, Vernon P, Renault D (2020) Spotlight on the invasion of a carabid beetle on an oceanic island over a 105-year period. Sci Rep 10:17103

Lumpkin R, Centurioni L (2019) Global Drifter Program quality-controlled 6-hour interpolated data from ocean surface drifting buoys. NOAA Natl Center Environ Inform. https://doi.org/10.25921 /7ntx-z961

Neumann D, Woermann D (2009) Physical conditions for trapping air by a microtrichia covered insect cuticle during temporary submersion. Naturwissenschaften 96:933-941

Peck SB (1994) Aerial dispersal of insects between and to islands in the Galápagos archipelago, Ecuador. Ann Entomol Soc Am $87: 218-224$

Pertierra LR, Bartlett JC, Duffy G, Vega GC, Hughes KA, Hayward SAL, Convey P, Olalla-Tárraga MA, Aragón P (2020) Combining correlative and mechanistic niche models with human activity data to elucidate the invasive potential of a sub-Antarctic insect. J Biogeogr 7:658-673

Pugh PJA (1997) Acarine colonisation of Antarctica and the islands of the Southern Ocean: the role of zoochoria. Polar Rec 33:113-122

Pyšek P et al (2020) Scientists' warning on invasive alien species. Biol Rev 95:1511-1534. https://doi.org/10.1111/brv.12627

Simões FL, Contador T, Rendoll J, Pérez C, Hayward SAL, Turner E, Convey P (2020) Distribution and habitat preferences of the newly rediscovered Telmatogeton magellanicus (Jacobs 1900 (Diptera: Chironomidae) on NavarinoIsland, Chile. Insects. https://doi. org/10.3390/insects11070442

Sugg P, Edwards JS, Baust J (1983) Phenology and life history of Belgica antarctica, an Antarctic midge (Diptera: Chironomidae). Ecol Entomol 8:105-113

Thompson AF, Heywood KJ, Thorpe SE, Renner AH, Trasviña A (2009) Surface circulation at the tip of the Antarctic Peninsula from drifters. J Phys Oceanogr 39:3-26

Vorburger C, Lancaster M, Sunnucks P (2003) Environmentally related patterns of reproductive modes in the aphid Myzus persicae and the predominance of two 'superclones' in Victoria, Australia. Mol Ecol 12:3493-3504

Publisher's Note Springer Nature remains neutral with regard to jurisdictional claims in published maps and institutional affiliations. 